\title{
Mutation of a highly conserved isoleucine disrupts hydrophobic interactions in the $\alpha \beta$ spectrin self-association binding site
}

\author{
Patrick G Gallagher ${ }^{1}$, Zhushan Zhang², Jon S Morrow² and Bernard G Forget ${ }^{3,4}$ \\ ${ }^{1}$ Department of Pediatrics; ${ }^{2}$ Department of Pathology; ${ }^{3}$ Department of Internal Medicine and ${ }^{4}$ Department of \\ Genetics, Yale University School of Medicine, New Haven, CT, USA
}

\begin{abstract}
We studied an infant with severe neonatal hemolytic anemia and hyperbilirubinemia that evolved into a partially compensated ellipto-poikilocytic anemia. His father had typical elliptocytosis. Their erythrocyte membranes demonstrated structural and functional defects in spectrin. Genetic studies revealed that the proband and his father were heterozygous for an $\alpha$-spectrin mutation, lle24Thr, in the $\alpha \beta$ spectrin self-association binding site. The proband also carried the low expression allele $\alpha^{L E L Y}$ in trans, influencing the clinical phenotype. The importance of isoleucine in this position of the proposed triple helical model of spectrin repeats is highlighted by its evolutionary conservation in all $\alpha$ spectrins from Drosophila to humans. Molecular modeling demonstrated that replacement of a hydrophobic isoleucine with a hydrophilic threonine disrupts highly conserved hydrophobic interactions in the interior of the spectrin triple helix critical for spectrin function. Laboratory Investigation (2004) 84, 229-234, advance online publication, 8 December 2003; doi:10.1038/labinvest.3700029
\end{abstract}

Keywords: spectrin; mutation; elliptocytosis; pyropoikilocytosis; dynamic molecular modeling

Spectrin, the principal structural component of the erythrocyte membrane, is also the most abundant protein, comprising $25-30 \%$ of membrane protein. In the red cell, spectrin functions include maintenance of cellular shape, regulation of lateral movement of integral membrane proteins, and provision of structural support for the lipid bilayer. ${ }^{1}$ Spectrin is composed of two subunits, $\alpha$ and $\beta$ spectrin, that despite some similarities are distinct proteins encoded by separate genes. ${ }^{2-6} \alpha$ and $\beta$ spectrin chains intertwine in an antiparallel manner to form $\alpha \beta$ heterodimers. The $\alpha \beta$ heterodimers selfassociate to form tetramers and oligomers, the primary functional unit of spectrin in the red cell. ${ }^{1}$

Detailed study of $\alpha$ and $\beta$ spectrin, including cDNA cloning, has yielded a better understanding of these important membrane proteins. Knowledge of the primary structure of spectrin has allowed determination of the precise genetics defects in cases of hereditary elliptocytosis (HE) and hereditary pyropoikilocytosis (HPP). ${ }^{6}$ Analyses of these mutations have provided important information on the structure and function of spectrin in the red cell

Correspondence: PG Gallagher, Department of Pediatrics, Yale University School of Medicine, 333 Cedar Street, PO Box 208064, New Haven, CT 06520-8064, USA.

E-mail: patrick.gallagher@yale.edu

Received 8 September 2003; revised 17 October 2003; accepted 22 October 2003; published online 8 December 2003 and shed additional insight into the pathogenesis of these disorders.

Of particular importance to our understanding of spectrin structure and function has been the identification of mutations in the regions of $\alpha$ and $\beta$ spectrin critical for self-association. ${ }^{7,8}$ This report describes a novel $\alpha$-spectrin mutation, Ile24Thr, discovered in an elliptocytosis/poikilocytosis kindred that is located in the region of the $\alpha \beta$-spectrin self-association binding site. This mutation disrupts highly conserved hydrophobic interactions in the interior of the spectrin triple helix that are critical for $\alpha \beta$ spectrin self-association, highlighting the importance of isoleucine 24 in spectrin structure and function.

\section{Materials and methods}

Erythrocyte Membrane Preparation And Quantitation of Spectrin Content

Erythrocyte membranes were prepared from peripheral blood as previously described. ${ }^{9,10}$ Membrane proteins were analyzed by electrophoresis in SDSPAGE either with a 5-15\% polyacrylamide gradient as described by Laemmli ${ }^{11}$ or using a $3.5 \%$ polyacrylamide gel as described by Fairbanks et al. ${ }^{9}$ To estimate spectrin/band-3 ratios, SDS polyacrylamide slab gels were scanned after Coomassie blue 
Table 1 Oligonucleotide primers

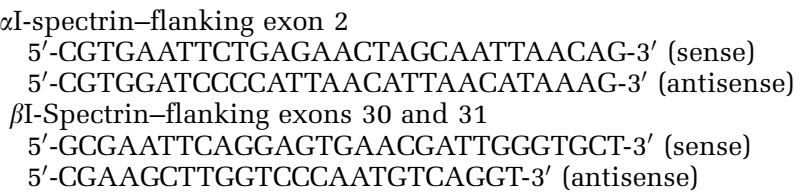

staining using a DU8 spectrophotometer (Beckman Instruments, Inc., Fullerton, CA, USA at $550 \mathrm{~nm}$.

\section{Study of Spectrin Dimer-Tetramer Equilibrium}

Spectrin was extracted by incubating ghosts overnight at $4^{\circ} \mathrm{C}$ in low ionic strength buffer. ${ }^{12}$ The content of spectrin dimers and tetramers was determined by nondenaturing gel electrophoresis as described. ${ }^{13}$

\section{Limited Trypic Digestion of Spectrin}

Limited tryptic digests of spectrin extracts were prepared as described. ${ }^{10}$ Spectrin peptides were separated by two-dimensional gel electrophoresis with isoelectric focusing (IEF) as described by O'Farrell ${ }^{14}$ modified by Speicher et al. ${ }^{15}$

\section{Amplification, Subcloning, and Nucleotide Sequencing of Amplified Genomic DNA}

Genomic DNA was amplified, subcloned, and sequenced as described. ${ }^{16}$ Oligonucleotide primers used to amplify exon 2 of the human $\alpha$-spectrin gene and exons 30 and 31 of the $\beta$-spectrin gene are listed in Table 1.

\section{Identification of the $\alpha^{\mathrm{LELY}}$ Allele}

The $\alpha^{\text {LELY }}$ allele was determined using a PCRamplification techniques as described. ${ }^{17}$

\section{Dynamic Molecular Modeling}

Dynamic molecular modeling of the spectrin selfassociation domain was performed as described..$^{18}$ These computations place the starting structure of the spectrin self-association domain in a 6 - $\AA$ water shell that contains $\sim 111000$ water molecules. The application of this approach and its fidelity has been described. ${ }^{16,18}$

\section{Results}

\section{Patients}

The proband, an African-American male, had hemolytic anemia and extreme jaundice in the neonatal period requiring intensive phototherapy. His hematocrit decreased from 42 to $22 \%$ in the first 2 weeks of life. Blood smear showed hemolysis and elliptocytosis. At 9 month-of-age, the spleen tip was palpable and the liver edge was $1 \mathrm{~cm}$ below the costal margin. The hematocrit was $30 \%$, and the reticulocyte count $3 \%$. The blood smear showed numerous elliptocytes and significant numbers of poikilocytes and schistocytes. The father's hematocrit was $43 \%$, and the reticulocyte count $3.9 \%$. His blood smear showed occasional elliptocytes. Blood smear and hematologic indices of the mother were normal.

\section{Studies of Erythrocyte Membrane Proteins}

Qualitative and quantitative analyses of erythrocyte membranes

One-dimensional SDS-PAGE analyses of erythrocyte membranes from the proband and his parents were qualitatively normal (not shown). Quantitative analyses of spectrin content, measured by the ratio of spectrin to band 3 was normal in the mother (1.1) and father (1.04), and decreased in the proband (0.91), compared to that of a normal control (1.0).

\section{Limited tryptic digestion of spectrin}

Limited tryptic digestion of normal spectrin followed by two-dimensional gel electrophoresis yields a pattern of five major proteolytically resistant domains of $\alpha$ spectrin and four proteolytically resistant domains of $\beta$ spectrin. ${ }^{15,19,20}$ The $80 \mathrm{kDa} \alpha \mathrm{I}$ domain encodes the $\mathrm{NH}_{2}$-terminus of $\alpha$ spectrin that interacts with sequences from the 17 th repeat of $\beta$ spectrin to form the binding site for spectrin selfassociation. ${ }^{21,22}$

Limited tryptic digestion of spectrin followed by two-dimensional gel electrophoresis with IEF (Figure 1) revealed new peptides of $74 \mathrm{kDa}$ in samples from the proband as well as in his father. Increased

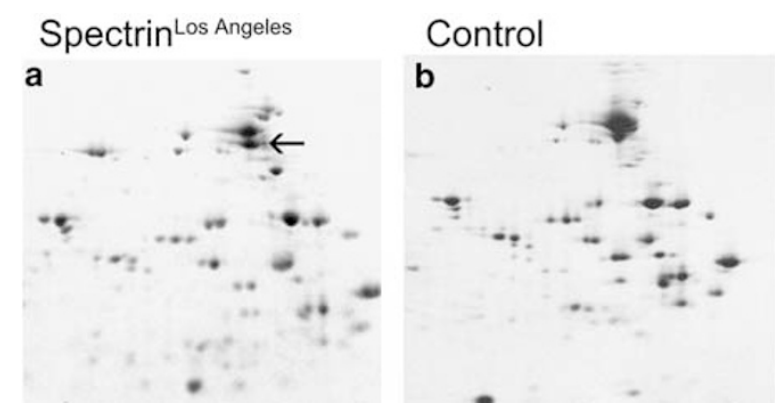

Figure 1 Limited tryptic digestion of spectrin. Red cell spectrin from members of the spectrin ${ }^{\text {Los }}$ Angeles kindred was partially digested with trypsin and fractionated by two-dimensional gel electrophoresis with IEF (SDS/PAGE with IEF). Spectrin digests from the father (a) demonstrate increased amounts of a $74 \mathrm{kDa}$ spectrin peptide (arrow), located just below the $80 \mathrm{kDa} \alpha \mathrm{I}$ domain peptide, compared with normal (b). Digests from the proband demonstrated increased amounts of the $74 \mathrm{kDa} \alpha \mathrm{I}$ domain peptide (not shown). In tryptic digests from the mother, the $\alpha$ I domain peptide was normal. 


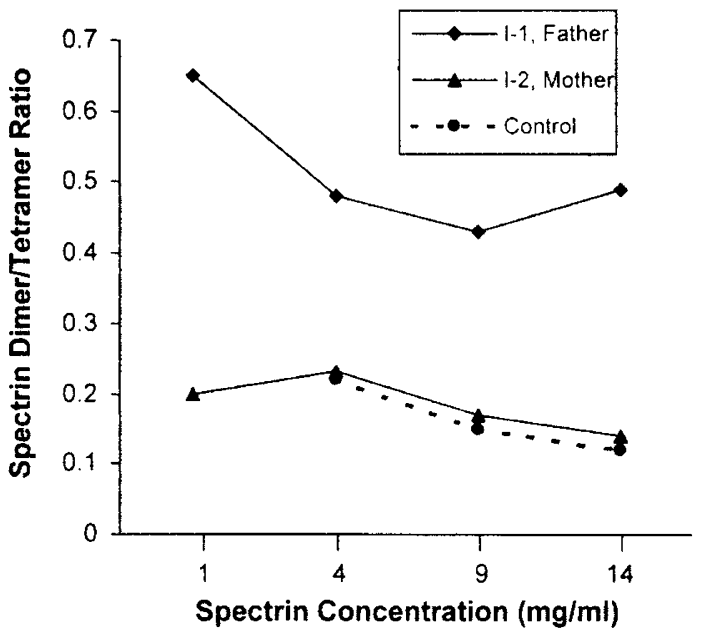

Figure 2 Spectrin self-association assays. Studies of spectrin selfassociation were performed using spectrin extracted from erythrocyte membrane ghosts at low ionic strength at $4{ }^{\circ} \mathrm{C}$ and then equilibrated at various concentrations. The increased amounts of spectrin dimers compared with tetramers at higher concentrations of the father's spectrin indicate a moderate degree of impairment of spectrin self-association.

amounts of the $\alpha \mathrm{I} / 74 \mathrm{kDa}$ peptide have been associated with structural defects of spectrin in individuals with HE and HPP.

Digests also revealed polymorphisms of the $\alpha$ II domain of spectrin..$^{23,24}$ The mother had polymorphisms of type 2 and type 4; the father, types 1 and 4 ; and the proband, type 4 only. Therefore, in this family, the $\alpha \mathrm{I} / 74 \mathrm{kDa}$ abnormality is associated with an $\alpha$-spectrin gene that also carries the type 4 polymorphism of the $\alpha$ II domain.

\section{Spectrin self-association}

Studies of spectrin's ability to self-associate were performed using spectrin extracted from erythrocyte ghosts under low ionic strength. The impaired formation of tetramers as a function of spectrin concentration is apparent in the elliptocytic father compared to the hematologically normal mother and a control (Figure 2). These studies indicate a moderate degree of impairment in spectrin selfassociation. In general, the degree of impairment of spectrin self-association parallels clinical severity in patients with HE or HPP. ${ }^{25,26}$ Insufficient spectrin was available from the proband to perform these studies.

\section{Molecular Genetic Analyses}

\section{Nucleotide sequencing}

Mutations associated with the variant $74 \mathrm{kDa}$ peptide of the $\alpha$ I domain of spectrin have been identified in the regions of the $\alpha \mathrm{I}$ and $\beta \mathrm{I}$ spectrin genes encoding the binding site of spectrin selfassociation. This corresponds to exon 2 of $\alpha \mathrm{I}-$ spectrin gene and exons $30-31$ of the $\beta$ I-spectrin gene. ${ }^{27}$ Genomic DNA from the proband correspond- ing to exon 2 of the $\alpha \mathrm{I}$-spectrin gene and exons 30-31 of the $\beta$ I-spectrin gene was amplified by PCR. Nucleotide sequence analysis of these amplification products revealed heterozygosity for a single nucleotide substitution (ATC to ACC) that changes an isoleucine (aliphatic, hydrophobic) to a threonine (hydroxyl, hydrophilic) at codon 24 of the $\alpha \mathrm{I}-$ spectrin chain. We have named this mutation spectrin $^{\text {Los Angeles. }}$

\section{PCR-based mutation detection}

The authenticity of this mutation was confirmed by restriction enzyme digestion of amplified genomic DNA. The spectrin ${ }^{\text {Los }}$ Angeles mutation disrupts an XhoII restriction enzyme site, PuGATCPy, allowing for rapid PCR-based detection in genomic DNA of each family member. Oligonucleotide primers (Table 1) flanking exon 2 of the $\alpha$-spectrin gene amplify a fragment of $372 \mathrm{bp}$. Amplified genomic DNA fragment from a normal individual and the mother digested into fragments of 56,81 , and $235 \mathrm{bp}$. Amplified genomic DNA fragments from the proband and his father yielded fragments of 56, 81, 235, and $316 \mathrm{bp}$, indicating heterozygosity for the spectrin $^{\text {Los Angeles }}$ mutation.

$\alpha^{L E L Y}$ allele

A PCR-based detection method was utilized to determine the status of the low expression allele $\alpha^{\text {LELY }}{ }^{17}$ The proband and his mother are heterozygous for the $\alpha^{\mathrm{LELY}}$ allele (not shown). The father lacks the $\alpha^{\mathrm{LELY}}$ allele. Thus, compared to the elliptocytic father without the $\alpha^{\mathrm{LELY}}$ allele, in the proband, inheritance of the $\alpha^{\mathrm{LELY}}$ allele in trans is likely to increase the relative expression of the mutant spectrin $^{\text {Los }}$ Angeles allele, thereby worsening the clinical phenotype.

\section{Dynamic Molecular Modeling}

The spectrin ${ }^{\text {Los Angeles }}$ mutation occurs at position 79 of partial repeat 1 within helix 3 of the proposed triple helical conformational model of spectrin repeats, corresponding to position $\mathrm{C} 4$ of the crystallographic structure of the spectrin repeat. ${ }^{2,28}$ Most mutations of the $80 \mathrm{kDa} \alpha \mathrm{I}$ domain of spectrin occur in helix 3 of the proposed model and are often at or adjacent to highly conserved residues of the homologous 106-amino-acid repeats of spectrin. ${ }^{27}$ The importance of isoleucine in this residue is highlighted by its evolutionary conservation in all reported $\alpha$ spectrins from Drosophila to humans (Table 2). A previous mutation in codon 24, Ile24Ser spectrin $^{\text {Lograno }}$, was described in a French kindred, ${ }^{34}$ further indicating the importance of codon 24 in spectrin function.

\section{Molecular modeling}

Development of dynamic molecular modeling allows prediction of the conformational rearrangements in the predicted structure induced by point 
Table 2 Evolutionary conservation of isoleucine in position 79 of partial repeat 1 of the proposed triple helical model of $\alpha$-spectrin

\begin{tabular}{|c|c|c|}
\hline Sequence & Species and Isoform & References \\
\hline TAEEIQERR & Human $\alpha$ I, wild type & Sahr et $a l^{3}$ \\
\hline TAEETQERR & Human $\alpha \mathrm{I}$, spectrin ${ }^{\mathrm{Los}}$ Angeles & This report \\
\hline TAEETQYHRR & Murine $\alpha \mathrm{I}$ & Wandersee et $a l^{29}$ \\
\hline TAEDİQERR & Human $\alpha$ II & Moon and McMahon ${ }^{30}$ \\
\hline TAEDĪQERR & Rat $\alpha$ II & Hong and Doyle ${ }^{31}$ \\
\hline TAEDİQERR & Chicken & Wasenius et $a l^{32}$ \\
\hline TVEDĪQERR & Drosophila & Dubreuil et $a l^{33}$ \\
\hline
\end{tabular}

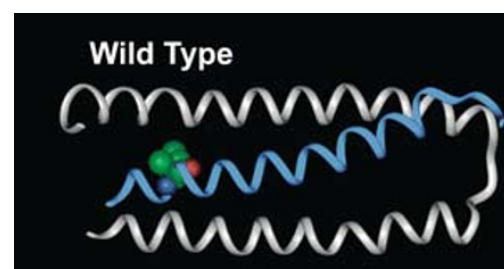

Spectrin Los Angeles

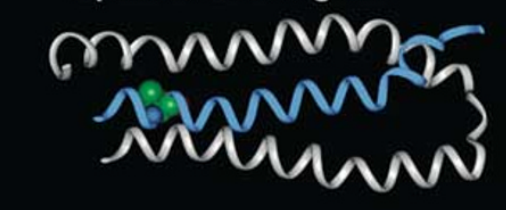

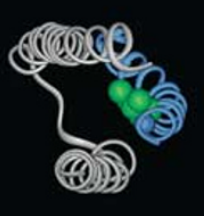

\begin{abstract}
.
\end{abstract}

\section{西}

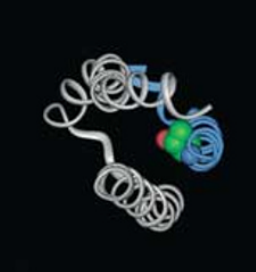

Figure 3 Dynamic molecular modeling of the structural effects of the spectrin ${ }^{\text {Los Angeles }}$ mutation. A triple helical repeat representing the $\alpha \beta$ spectrin self-association contact site is shown. The $\mathrm{A}$ and $\mathrm{B}$ helices of $\beta \mathrm{I}$ spectrin are shown in white and the $\mathrm{C}$ helix of $\alpha \mathrm{I}$ spectrin is shown in blue. Amino acid 24, the location of the spectrin $^{\text {LosAngeles }}$ mutation is shown as a space-filling representation. Dynamic molecular modeling indicates that replacement of a hydrophobic isoleucine with a hydrophilic threonine disrupts conserved hydrophobic interactions in the interior of the triple helix and disrupts the conformation of the normal $\alpha \beta$ spectrin self-association domain. Lateral (left) and end-on (right) views are shown.

mutations. Modeling of the Ile24Thr mutation is shown in Figure 3. This mutation disrupts critical hydrophobic interactions between helix $\mathrm{C}$ and helix A (F2014 of $\beta$ spectrin). ${ }^{28}$ In general, interactions of helix $\mathrm{C}$ with helices $\mathrm{A}$ and $\mathrm{B}$ provide stability to the spectrin self-association unit. ${ }^{18}$

In previous studies, comparison of the degree of predicted structural disruption in the self-association site with clinical severity revealed a strong correlationr. ${ }^{18}$ The degree of structural deviation, as derived by the root-mean-square deviation from the predicted spectrin backbone, for the Ile24Thr spectrin $^{\text {Los Angeles }}$ mutation was 3.296 Angstroms (normal $2.846 \AA$ ). Thus, the predicted structural disruption of the spectrin ${ }^{\text {Los Angeles }}$ mutation correlates with the clinical severity observed.

\section{Discussion}

The model of spectrin as a protein-containing multiple $\alpha$-helical, coiled coil, triple helical repeats was first predicted by direct protein sequencing. ${ }^{2}$ Refinements and phasing of the model have been made as determination of the primary structure,,$^{3,4}$ $\mathrm{X}$-ray, nuclear magnetic resonance, and spectroscopic studies of spectrin have been completed. ${ }^{28,35-43}$ These studies predict that the first and third helices are parallel and the second helix is antiparallel. The amphipathic repeats are stabilized by hydrophobic interactions of each repeat at the interior core of each repeat.

Heptad periodicity, detectable from inspection of the primary sequence and in the three-dimensional structure, has been suggested to promote stable folding of a single spectrin repeat. ${ }^{4}$ The majority of conserved amino acids in spectrin repeats are amino acids that occupy heptad positions $a$ and $d$ that make up the hydrophobic core of the coiled coil. This is true for isoleucine 24 , located at position $\mathrm{C} 4$ in heptad $d$, which is one of the most highly conserved hydrophobic residues in all spectrin repeats. ${ }^{38}$ In addition to the hydrophobic packing in the core, electrostatic interactions between charged side chains of various amino acids, primarily at heptad positions $e$ and $g$, help stabilize the repeat fold ${ }^{45}$ and contribute to the formation of stable dimers. ${ }^{46}$

Molecular modeling permits analysis of the key residues involved in spectrin inter- and intrachain interactions. Interestingly, the majority of $\alpha$-spectrin mutations associated with $\mathrm{HE}$ and HPP are predicted to disrupt hydrogen bond and salt bridge interactions. In only one other case, spectrin $^{\text {Lyon }},{ }^{47} \mathrm{~L} 49 \mathrm{~F}$, is there replacement of an amino acid directly involved in hydrophobic interactions.

Spectrin ${ }^{\text {Los Angeles }}$ was detected only in the heterozygous state, and when in trans, to the $\alpha^{\mathrm{LELY}}$ allele as occurs in the proband, is associated with a severe clinical phenotype. As noted by Zhang et $a l,{ }^{18}$ even though heterozygous $\alpha$-spectrin self-association binding site mutations are among those most commonly found in HE and HPP patients, homozygous mutations of the $\alpha$-spectrin self-association site have not been found, perhaps because complete disruption of spectrin self-association is incompatible with life. The significant disruption of hydrophobic interactions in the core of the $\alpha \beta$ spectrin repeat caused by the spectrin ${ }^{\text {Los }}$ Angeles mutation 
suggests that homozygosity for this mutation would also be incompatible with life.

\section{Acknowledgement}

This study is supported in part by grants from the National Institute of Health and the March of Dimes Birth Defects Foundation.

\section{References}

1 Morrow JS, Rimm DL, Kennedy SP, et al. Of membrane stability and mosaics: the spectrin cytoskeleton. In: Hoffman J, Jamieson J (eds). Handbook of Physiology. Oxford University Press: London, 1997, pp 485-540.

2 Speicher DW, Marchesi VT. Erythrocyte spectrin is comprised of many homologous triple helical segments. Nature 1970;311:177-180.

3 Sahr KE, Laurila P, Kotula L, et al. The complete cDNA and polypeptide sequences of human erythroid alphaspectrin. J Biol Chem 1990;265:4434-4443.

4 Winkelmann JC, Chang JG, Tse WT, et al. Full-length sequence of the cDNA for human erythroid betaspectrin. J Biol Chem 1990;265:11827-11832.

5 Winkelmann JC, Forget BG. Erythroid and nonerythroid spectrins. Blood 1993;81:3173-3185.

6 Walensky LD, Narla M, Lux SE. Disorders of the red blood cell membrane. In: Handin RI, Lux SE, Stossel TP (eds). Blood: Principles and Practice of Hematology, 2nd edn Lippincott Williams Wilkins: Philadelphia, 2003, pp 1709-1858.

7 Delaunay J, Dhermy D. Mutations involving the spectrin heterodimer contact site: clinical expression and alterations in specific function. Semin Hematol 1993;30:21-33.

8 Tse WT, Lux SE. Red blood cell membrane disorders. Br J Haematol 1999;104:2-13.

9 Fairbanks G, Steck TL, Wallach DF. Electrophoretic analysis of the major polypeptides of the human erythrocyte membrane. Biochemistry 1971;10: 2606-2617.

10 Marchesi SL, Knowles WJ, Morrow JS, et al. Abnormal spectrin in hereditary elliptocytosis. Blood 1986;67:141-151.

11 Laemmli UK. Cleavage of structural proteins during the assembly of the head of bacteriophage T4. Nature 1970;227:680-685.

12 Ungewickell E, Gratzer W. Self-association of human spectrin. A thermodynamic and kinetic study. Eur J Biochem 1978;88:379-385.

13 Marchesi SL, Letsinger JT, Speicher DW, et al. Mutant forms of spectrin alpha-subunits in hereditary elliptocytosis. J Clin Invest 1987;80:191-198.

14 O'Farrell PH. High resolution two-dimensional electrophoresis of proteins. J Biol Chem 1975;250: 4007-4021.

15 Speicher DW, Morrow JS, Knowles WJ, et al. Identification of proteolytically resistant domains of human erythrocyte spectrin. Proc Natl Acad Sci USA 1980;77:5673-5677.

16 Gallagher PG, Petruzzi MJ, Weed SA, et al. Mutation of a highly conserved residue of betaI spectrin associated with fatal and near-fatal neonatal hemolytic anemia. J Clin Invest 1997;99:267-277.
17 Gallagher PG, Forget BG. Spectrin St Louis and the alpha $^{\text {LELY }}$ allele. Blood 1994;84:1686-1687.

18 Zhang Z, Weed SA, Gallagher PG, et al. Dynamic molecular modeling of pathogenic mutations in the spectrin self-association domain. Blood 2001;98: 1645-1653.

19 Morrow JS, Speicher DW, Knowles WJ, et al. Identification of functional domains of human erythrocyte spectrin. Proc Natl Acad Sci USA 1980;77:6592-6596.

20 Speicher DW, Morrow JS, Knowles WJ, et al. A structural model of human erythrocyte spectrin. Alignment of chemical and functional domains. J Biol Chem 1982;257:9093-9101.

21 Kennedy SP, Weed SA, Forget BG, et al. A partial structural repeat forms the heterodimer self-association site of all beta-spectrins. J Biol Chem 1994;269:11400-11408.

22 Speicher DW, DeSilva TM, Speicher KD, et al. Location of the human red cell spectrin tetramer binding site and detection of a related "closed" hairpin loop dimer using proteolytic footprinting. J Biol Chem 1993;268:4227-4235.

23 Knowles WJ, Bologna ML, Chasis JA, et al. Common structural polymorphisms in human erythrocyte spectrin. J Clin Invest 1984;73:973-979.

24 Gallagher PG, Kotula L, Wang Y, et al. Molecular basis and haplotyping of the alphaII domain polymorphisms of spectrin: application to the study of hereditary elliptocytosis and pyropoikilocytosis. Am J Hum Genet 1996;59:351-359.

25 Liu SC, Palek J, Prchal JT. Defective spectrin dimerdimer association with hereditary elliptocytosis. Proc Natl Acad Sci USA 1982;79:2072-2076.

26 Coetzer T, Palek J, Lawler J, et al. Structural and functional heterogeneity of alpha spectrin mutations involving the spectrin heterodimer selfassociation site: relationships to hematologic expression of homozygous hereditary elliptocytosis and hereditary pyropoikilocytosis. Blood 1990;75: 2235-2244.

27 Gallagher PG, Forget BG. Hematologically important mutations: spectrin variants in hereditary elliptocytosis and hereditary pyropoikilocytosis. Blood Cells Mol Dis 1996;22:254-258.

28 Yan Y, Winograd E, Viel A, et al. Crystal structure of the repetitive segments of spectrin. Science 1993;262:2027-2030.

29 Wandersee NJ, Birkenmeier CS, Gifford EJ, et al. Murine recessive hereditary spherocytosis, $\mathrm{sph} / \mathrm{sph}$, is caused by a mutation in the erythroid alpha-spectrin gene. Hematol J 2000;1:235-242.

30 Moon RT, McMahon AP. Generation of diversity in nonerythroid spectrins. Multiple polypeptides are predicted by sequence analysis of cDNAs encompassing the coding region of human nonerythroid alphaspectrin. J Biol Chem 1990;265:4427-4433.

31 Hong WJ, Doyle D. Cloning and analysis of cDNA clones for rat kidney alpha-spectrin. J Biol Chem 1989;264:12758-12764.

32 Wasenius VM, Saraste M, Knowles J, et al. Sequencing of the chicken non-erythroid spectrin cDNA reveals an internal repetitive structure homologous to the human erythrocyte spectrin. EMBO J 1985;4:1425-1430.

33 Dubreuil RR, Byers TJ, Sillman AL, et al. The complete sequence of Drosophila alpha-spectrin: conservation of structural domains between alpha-spectrins and alpha-actinin. J Cell Biol 1989;109:2197-2205. 
34 Parquet N, Devaux I, Boulanger L, et al. Identification of three novel spectrin alpha $\mathrm{I} / 74$ mutations in hereditary elliptocytosis: further support for a triplestranded folding unit model of the spectrin heterodimer contact site. Blood 1994;84:303-308.

35 Calvert R, Ungewickell E, Gratzer W. A conformational study of human spectrin. Eur J Biochem 1980;107: 363-367.

36 LaBrake CC, Wang L, Keiderling TA, et al. Fourier transform infrared spectroscopic studies of the secondary structure of spectrin under different ionic strengths. Biochemistry 1993;32:10296-10302.

37 Pascual J, Pfuhl M, Rivas G, et al. The spectrin repeat folds into a three-helix bundle in solution. FEBS Lett 1996;383:201-207.

38 Pascual J, Pfuhl M, Walther D, et al. Solution structure of the spectrin repeat: a left-handed antiparallel triplehelical coiled-coil. J Mol Biol 1997;273:740-751.

39 DeSilva TM, Harper SL, Kotula L, et al. Physical properties of a single-motif erythrocyte spectrin peptide: a highly stable independently folding unit. Biochemistry 1997;36:3991-3997.

40 Grum VL, Li D, MacDonald RI, et al. Structures of two repeats of spectrin suggest models of flexibility. Cell 1999;98:523-535.
41 Lenne PF, Raae AJ, Altmann SM, et al. States and transitions during forced unfolding of a single spectrin repeat. FEBS Lett 2000;476:124-128.

42 Mehboob S, Luo BH, Patel BM, et al. $\alpha \beta$ Spectrin coiled coil association at the tetramerization site. Biochemistry 2001;40:12457-12464.

43 Park S, Johnson ME, Fung LW. Nuclear magnetic resonance studies of mutations at the tetramerization region of human alpha spectrin. Blood 2002;100: 283-288.

44 Parry DA, Dixon TW, Cohen C. Analysis of the threealpha-helix motif in the spectrin superfamily of proteins. Biophys J 1992;61:858-867.

45 Djinovic-Carugo K, Gautel M, Ylanne J, et al. The spectrin repeat: a structural platform for cytoskeletal protein assemblies. FEBS Lett 2002;513: 119-123.

46 Broderick MJ, Winder SJ. Towards a complete atomic structure of spectrin family proteins. J Struct Biol 2002;137:184-193.

47 Morle L, Roux AF, Alloisio N, et al. Two elliptocytogenic alpha $\mathrm{I} / 74$ variants of the spectrin alpha I domain. Spectrin Culoz (GGT-GTT; alpha I 40 Gly--Val) and spectrin Lyon (CTT-TTT; alpha I 43 Leu-Phe). J Clin Invest 1990;86:548-554. 